\title{
Electronic Transport and Thermoelectric Properties of Te-Doped Tetrahedrites $\mathrm{Cu}_{12} \mathrm{Sb}_{4-\mathrm{y}} \mathrm{Te}_{\mathrm{y}} \mathrm{S}_{13}$
}

\author{
Sung-Gyu Kwak, Go-Eun Lee, and Il-Ho Kim* \\ Department of Materials Science and Engineering, Korea National University of Transportation, \\ Chungiu 27469, Republic of Korea
}

\begin{abstract}
Tetrahedrite is a promising thermoelectric material mainly due to its low thermal conductivity, a consequence of its complicated crystal structure. However, tetrahedrite has a high hole concentration; therefore, optimizing carrier concentration through doping is required to maximize the power factor. In this study, Te-doped tetrahedrites $\mathrm{Cu}_{12} \mathrm{Sb}_{4-\mathrm{y}} \mathrm{Te}_{\mathrm{y}} \mathrm{S}_{13}(0.1 \leq \mathrm{y} \leq 0.4)$ were prepared using mechanical alloying and hot pressing. The mechanical alloying successfully prepared the tetrahedrites doped with $\mathrm{Te}$ at the $\mathrm{Sb}$ sites without secondary phases, and the hot pressing produced densely sintered bodies with a relative density $>99.7 \%$. As the Te content increased, the lattice constant increased from 1.0334 to $1.0346 \mathrm{~nm}$, confirming the successful substitution of $\mathrm{Te}$ at the $\mathrm{Sb}$ sites. Te-doped tetrahedrites exhibited $\mathrm{p}$-type characteristics, which were confirmed by the positive signs of the Hall and Seebeck coefficients. The carrier concentration decreased but the mobility increased with Te content. The electrical conductivity was relatively constant at 323-723 K, and decreased with Te substitution from $2.6 \times 10^{4}$ to $1.6 \times 10^{4} \mathrm{Sm}^{-1}$ at $723 \mathrm{~K}$. The Seebeck coefficient increased with temperature and Te content, achieving values of $184-204 \mu \mathrm{VK}^{-1}$ at $723 \mathrm{~K}$. The thermal conductivity was $<1.0 \mathrm{Wm}^{-1} \mathrm{~K}^{-1}$, and decreased with increasing Te content. $\mathrm{Cu}_{12} \mathrm{Sb}_{3.9} \mathrm{Te}_{0.1} \mathrm{~S}_{13}$ exhibited the highest dimensionless figure of merit $(\mathrm{ZT}=0.80)$ at $723 \mathrm{~K}$, achieving a high power factor $\left(0.91 \mathrm{mWm}^{-1} \mathrm{~K}^{-2}\right)$ and a low thermal conductivity $\left(0.80 \mathrm{Wm}^{-1} \mathrm{~K}^{-1}\right)$.
\end{abstract}

(Received March 9, 2021; Accepted May 6, 2021)

Keywords: thermoelectric; tetrahedrite; mechanical alloying; hot pressing; doping

\section{INTRODUCTION}

Tetrahedrite $\left(\mathrm{Cu}_{12} \mathrm{Sb}_{4} \mathrm{~S}_{13}\right)$, a mineral composed of earthabundant and eco-friendly elements, has been studied as a potential thermoelectric material since it exhibits excellent performance with high electrical conductivity and low thermal conductivity $[1,2]$. PbTe-based materials are known to be excellent thermoelectric materials in the temperature range of 500-800 K. However, they consist of rare elements and toxic heavy metals. $\mathrm{Cu}_{12} \mathrm{Sb}_{4} \mathrm{~S}_{13}$ has a complex and highly symmetric cubic structure (space group $\mathrm{I} \overline{4} 3 \mathrm{~m}$ ) composed of $\mathrm{Cu}^{\mathrm{I}} \mathrm{S}_{4}$ tetrahedra, $\mathrm{Cu}^{\mathrm{II}} \mathrm{S}_{3}$ triangles, and $\mathrm{SbS}_{3}$ trigonal pyramids [3]. The low lattice thermal conductivity of tetrahedrite is due to the lone-pair electrons of the $\mathrm{Sb}$ atoms, which cause the

*Corresponding Author: Il-Ho Kim [Tel: +82-43-841-5387, E-mail: ihkim@ut.ac.kr] Copyright (c) The Korean Institute of Metals and Materials
$\mathrm{Cu}^{\mathrm{II}}$ atoms to oscillate anharmonically with low frequency and high amplitude in the S triangle plane [4-6].

Thermoelectric performance is evaluated using a dimensionless figure of merit $\left(\mathrm{ZT}=\alpha^{2} \sigma \kappa^{-1} \mathrm{~T}\right)$. Good thermoelectric materials should have a power factor $\left(\mathrm{PF}=\alpha^{2} \sigma\right)$ and low thermal conductivity ( $\kappa)$ at application temperature ( $\mathrm{T}$ in Kelvin), where $\alpha$ is the Seebeck coefficient and $\sigma$ is the electrical conductivity. Carrier concentration affects both the Seebeck coefficient and electrical conductivity, and these two parameters are trade-offs for the PF. In general, PF can be improved by optimizing the carrier concentration. To maximize PF and reduce the thermal conductivity of tetrahedrite simultaneously, studies have been conducted to reduce the hole concentration by substituting various elements for the $\mathrm{Cu}, \mathrm{Sb}$, and $\mathrm{S}$ sites [7-10]. Most studies on tetrahedrite have focused on the partial substitution of transition elements (e.g., $\mathrm{Fe}, \mathrm{Co}, \mathrm{Ni}, \mathrm{Zn}$ ) for the $\mathrm{Cu}$ sites; however, few studies have been reported on the doping of $\mathrm{Sb}$ 
or $\mathrm{S}$ sites.

The $\mathrm{Sb}$ sites of natural mineral tetrahedrite usually contain $\mathrm{As}, \mathrm{Bi}$, and Te atoms as impurities [11]; this has suggested studies on the substitution of $\mathrm{Sb}$ sites in synthetic tetrahedrite. Kwak et al. [12] reported $\mathrm{Bi}$-doped $\mathrm{Cu}_{12} \mathrm{Sb}_{4-\mathrm{y}} \mathrm{Bi}_{\mathrm{y}} \mathrm{S}_{13}(\mathrm{y}=0.1-$ $0.4)$ prepared by mechanical alloying (MA) and hot pressing (HP); $\mathrm{ZT}=0.88$ at $723 \mathrm{~K}$ for $\mathrm{Cu}_{12} \mathrm{Sb}_{3.9} \mathrm{Bi}_{0.1} \mathrm{~S}_{13}$. Kumar et al. [11] studied $\mathrm{Bi}$-doped $\mathrm{Cu}_{12} \mathrm{Sb}_{4-y} \mathrm{Bi}_{y} \mathrm{~S}_{13}(\mathrm{y}=0.2-0.8)$ synthesized by encapsulated melting (EM) and HP; ZT $=0.84$ at $673 \mathrm{~K}$ for $\mathrm{Cu}_{12} \mathrm{Sb}_{3.9} \mathrm{Bi}_{0.1} \mathrm{~S}_{13}$. Bouyrie et al. [13] examined Te-doped $\mathrm{Cu}_{12} \mathrm{Sb}_{4-y} \mathrm{Te}_{y} \mathrm{~S}_{13}(\mathrm{y}=0.5-1.75)$ prepared by EM and spark plasma sintering (SPS); $\mathrm{ZT}=0.65$ at $623 \mathrm{~K}$ for $\mathrm{Cu}_{12} \mathrm{Sb}_{3.39}$ $\mathrm{Te}_{0.61} \mathrm{~S}_{13}$. Lu et al. [14] reported Te-doped $\mathrm{Cu}_{12} \mathrm{Sb}_{4-\mathrm{y}} \mathrm{Te}_{\mathrm{y}} \mathrm{S}_{13}$ (y $=0-1)$ synthesized by $\mathrm{EM}$ and $\mathrm{HP} ; \mathrm{ZT}=0.92$ at $723 \mathrm{~K}$ for $\mathrm{Cu}_{12} \mathrm{Sb}_{3} \mathrm{TeS}_{13}$.

In this study, Te-doped tetrahedrites $\mathrm{Cu}_{12} \mathrm{Sb}_{4-\mathrm{y}} \mathrm{Te}_{\mathrm{y}} \mathrm{S}_{13}$ ( $\mathrm{y}=$ 0.1-0.4) were prepared by MA and HP using a solid-state synthesis method, and charge transport and thermoelectric properties were examined.

\section{EXPERIMENTAL PROCEDURE}

Te-doped $\mathrm{Cu}_{12} \mathrm{Sb}_{4-\mathrm{y}} \mathrm{Te}_{\mathrm{y}} \mathrm{S}_{13}$ ( $\left.\mathrm{y}=0.1-0.4\right)$ was synthesized by MA. All chemicals were purchased from Kojundo Chemical Laboratory Co., Saitama, Japan. Cu (purity 99.9\%, <45 $\mu \mathrm{m}$ ), $\mathrm{Sb}$ (purity 99.999\%, <150 $\mu \mathrm{m}$ ), Te (purity 99.999\%, <150 $\mu \mathrm{m}$ ), and S (purity $99.99 \%,<75 \mu \mathrm{m}$ ) powders were weighed to obtain a stoichiometric composition. Mixed elemental powders and stainless-steel balls (diameter $5 \mathrm{~mm}$ ) were loaded in a hardened steel jar at a weight ratio (ball-topowder ratio) of 20. MA was performed at $350 \mathrm{rpm}$ for $24 \mathrm{~h}$ in an Ar atmosphere using a planetary ball mill (Pulverisette5, Fritsch, Germany). To consolidate the synthesized powder, $\mathrm{HP}$ was conducted at $723 \mathrm{~K}$ for $2 \mathrm{~h}$ under a pressure of 70 using a uniaxial vacuum hot pressing system (VHP, Jeongmin VSL, Korea).

X-ray diffraction (XRD; D8-Advance, Bruker, Germany) was performed with $\mathrm{Cu}-\mathrm{K} \alpha$ radiation to analyze the phases of the synthetic powders and sintered specimens. Scanning electron microscopy (SEM; Quanta400, FEI, USA) was used to observe the fractured surfaces of the HP specimens, and energy-dispersive X-ray spectroscopy (EDS; Quantax200, Bruker, Germany) was employed to conduct the elemental analysis. The energy levels of the elements were $\mathrm{Cu}-\mathrm{L} \alpha$ (0.928 eV), Sb-L $\alpha$ (3.604 eV), Te-L $\alpha$ (3.768 eV), and S-K $\alpha$ $(2.309 \mathrm{eV})$. The electronic transport parameters (Hall coefficient, carrier concentration, and mobility) were examined under a direct current (DC) of $100 \mathrm{~mA}$ and a magnetic field of 1 Tesla using the van der Pauw method (7065, Keithley, USA). The thermoelectric properties were measured at temperatures from 323 to $723 \mathrm{~K}$. The DC four-probe method (ZEM-3, Advance Riko, Japan) was used to measure the electrical conductivity and Seebeck coefficient. The laser flash method (TC-9000H, Advance Riko, Japan) was employed to determine the thermal conductivity after measuring the thermal diffusivity, specific heat, and density. Finally, the PF and ZT were evaluated.

\section{RESULTS AND DISCUSSION}

XRD patterns of the $\mathrm{Cu}_{12} \mathrm{Sb}_{4-\mathrm{y}} \mathrm{Te}_{\mathrm{y}} \mathrm{S}_{13}$ prepared by the MAHP process are shown in Figure 1. The diffraction peaks of all the specimens matched the ICDD standard diffraction data (PDF\#024-1318, space group $\mathrm{I} \overline{4} 3 m$ ). The diffraction angles shifted to a lower value with increased Te doping (y). The lattice constant increased from 1.0334 to $1.0346 \mathrm{~nm}$ with Te doping, as shown in Table 1. Lu et al. [14] prepared Tedoped tetrahedrites $\mathrm{Cu}_{12} \mathrm{Sb}_{4-\mathrm{y}} \mathrm{Te}_{\mathrm{y}} \mathrm{S}_{13}(\mathrm{y}=0.1-1.0)$ using the EM-HP method and reported slight changes in the lattice constant because the difference between the covalent radii of

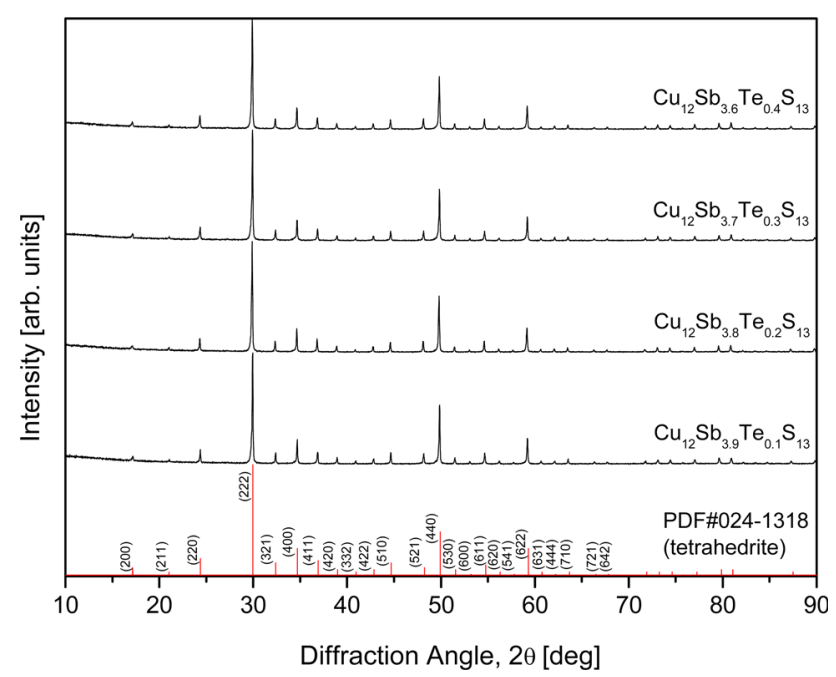

Fig. 1. XRD patterns of $\mathrm{Cu}_{12} \mathrm{Sb}_{4-\mathrm{y}} \mathrm{Te}_{\mathrm{y}} \mathrm{S}_{13}$ tetrahedrites prepared by the MA-HP process. 
Table 1. Chemical, physical, and electronic transport properties of $\mathrm{Cu}_{12} \mathrm{Sb}_{4-\mathrm{y}} \mathrm{Te}_{\mathrm{y}} \mathrm{S}_{13}$.

\begin{tabular}{|c|c|c|c|c|c|c|c|}
\hline \multicolumn{2}{|c|}{ Composition } & \multirow{2}{*}{$\begin{array}{c}\text { Relative } \\
\text { density } \\
{[\%]}\end{array}$} & \multirow{2}{*}{$\begin{array}{c}\text { Lattice } \\
\text { constant } \\
{[\mathrm{nm}]}\end{array}$} & \multirow{2}{*}{$\begin{array}{l}\text { Hall coefficient } \\
\qquad\left[\mathrm{cm}^{3} \mathrm{C}^{-1}\right]\end{array}$} & \multirow{2}{*}{$\begin{array}{c}\text { Carrier } \\
\text { concentration } \\
{\left[10^{18} \mathrm{~cm}^{-3}\right]}\end{array}$} & \multirow{2}{*}{$\begin{array}{l}\text { Mobility } \\
{\left[\mathrm{cm}^{2} \mathrm{~V}^{-1} \mathrm{~s}^{-1}\right]}\end{array}$} & \multirow{2}{*}{$\begin{array}{c}\text { Lorenz } \\
\text { number } \\
{\left[10^{-8} \mathrm{~V}^{2} \mathrm{~K}^{-2}\right]}\end{array}$} \\
\hline Nominal & Experimental & & & & & & \\
\hline $\mathrm{Cu}_{12} \mathrm{Sb}_{3.9} \mathrm{Te}_{0.1} \mathrm{~S}_{13}$ & $\mathrm{Cu}_{13.43} \mathrm{Sb}_{3.95} \mathrm{Te}_{0.06} \mathrm{~S}_{11.54}$ & 100.0 & 1.0334 & 1.76 & 3.56 & 414 & 1.80 \\
\hline $\mathrm{Cu}_{12} \mathrm{Sb}_{3.8} \mathrm{Te}_{0.2} \mathrm{~S}_{13}$ & $\mathrm{Cu}_{14.56} \mathrm{Sb}_{3.72} \mathrm{Te}_{0.22} \mathrm{~S}_{10.48}$ & 99.8 & 1.0344 & 2.09 & 2.99 & 368 & 1.77 \\
\hline $\mathrm{Cu}_{12} \mathrm{Sb}_{3.7} \mathrm{Te}_{0.3} \mathrm{~S}_{13}$ & $\mathrm{Cu}_{14.19} \mathrm{Sb}_{3.80} \mathrm{Te}_{0.32} \mathrm{~S}_{10.67}$ & 99.7 & 1.0345 & 2.41 & 2.59 & 361 & 1.75 \\
\hline $\mathrm{Cu}_{12} \mathrm{Sb}_{3.6} \mathrm{Te}_{0.4} \mathrm{~S}_{13}$ & $\mathrm{Cu}_{13.60} \mathrm{Sb}_{3.68} \mathrm{Te}_{0.36} \mathrm{~S}_{11.34}$ & 99.7 & 1.0346 & 3.58 & 1.74 & 497 & 1.74 \\
\hline
\end{tabular}
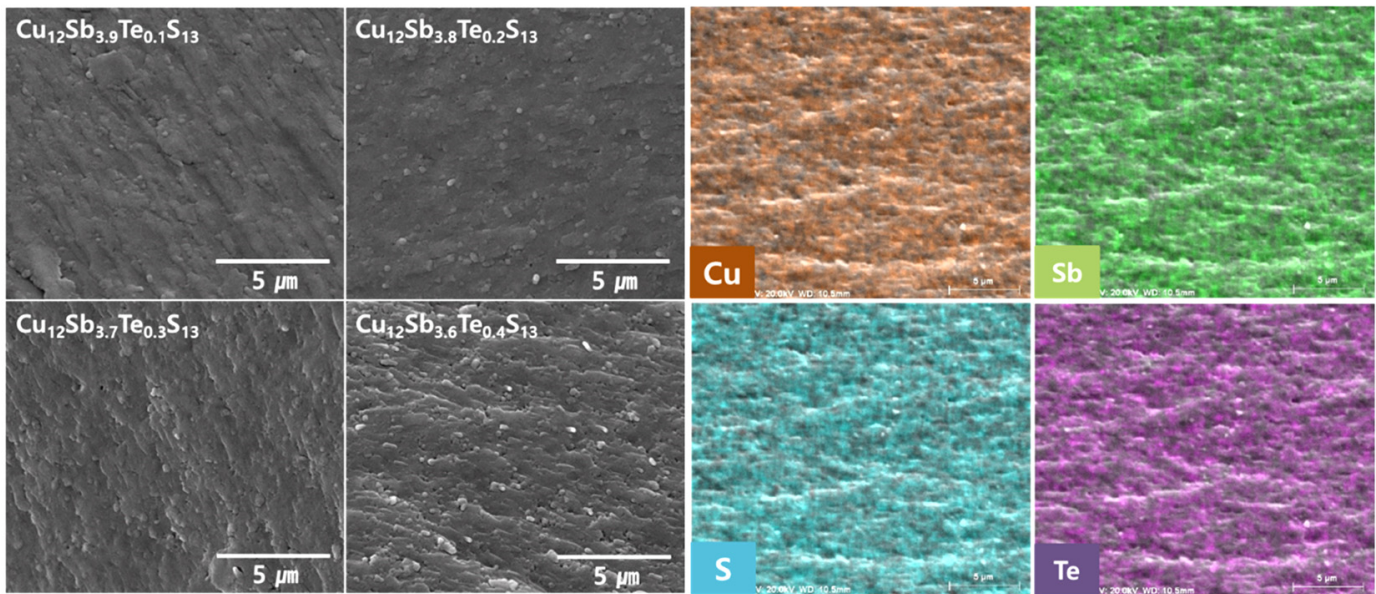

Fig. 2. $S E M$ images of fractured surfaces for $\mathrm{Cu}_{12} \mathrm{Sb}_{4-\mathrm{y}} \mathrm{Te}_{\mathrm{y}} \mathrm{S}_{13}$ and EDS elemental maps of $\mathrm{Cu}, \mathrm{Sb}, \mathrm{S}$, and Te for $\mathrm{Cu}_{12} \mathrm{Sb}_{3.6} \mathrm{Te}_{0.4} \mathrm{~S}_{13}$.

$\mathrm{Sb}^{3+}(0.139 \mathrm{~nm})$ and $\mathrm{Te}^{4+}(0.138 \mathrm{~nm})$ was small.

Figure 2 displays SEM images of the $\mathrm{Cu}_{12} \mathrm{Sb}_{4-\mathrm{y}} \mathrm{Te}_{\mathrm{y}} \mathrm{S}_{13}$ prepared by the MA-HP process. The samples sintered by HP exhibited high relative densities of $99.7 \%-100.0 \%$. No significant changes in the microstructure were observed when Te content was varied. Unreacted residual elements and secondary phases were not observed. The EDS elemental maps of $\mathrm{Cu}_{12} \mathrm{Sb}_{3.6} \mathrm{Te}_{0.4} \mathrm{~S}_{13}$ showed that the constituent elements were uniformly distributed. As shown in Table 1, the experimental composition agreed well with the nominal composition; however, the $\mathrm{Cu}$ content was relatively high, and the $\mathrm{S}$ content was relatively low. This was interpreted as errors in the compositional analysis and volatilization of S during HP.

Figure 3 presents the carrier concentration and mobility of $\mathrm{Cu}_{12} \mathrm{Sb}_{4-\mathrm{y}} \mathrm{Te}_{\mathrm{y}} \mathrm{S}_{13}$, and Table 1 summarizes their average values from measuring the Hall coefficient 20 times. Te-doped tetrahedrites exhibited positive Hall coefficients, confirming they are p-type semiconductors. The carrier (hole) concentration decreased from $3.56 \times 10^{18}$ to $1.74 \times 10^{18} \mathrm{~cm}^{-3}$ as Te content increased. Mobility is generally inversely related to carrier concentration in a nondegenerate semiconductor, and its

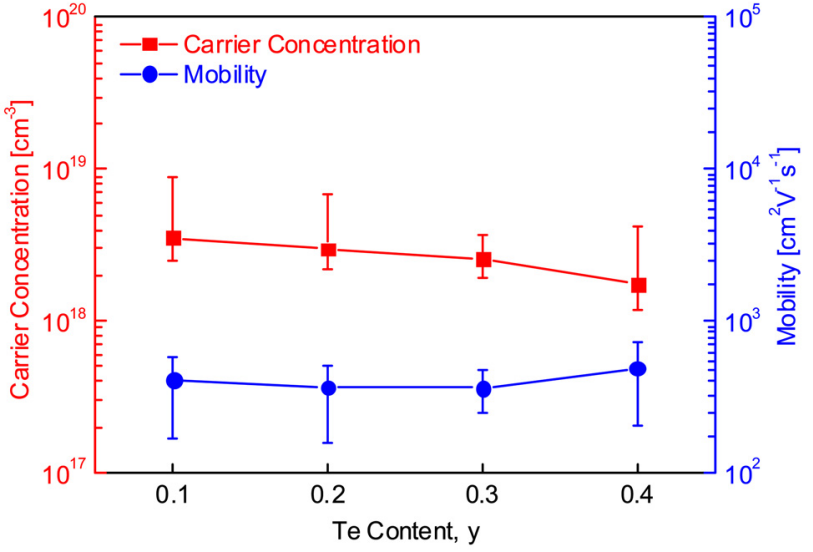

Fig. 3. Carrier concentration and mobility for $\mathrm{Cu}_{12} \mathrm{Sb}_{4-y} \mathrm{Te}_{\mathrm{y}} \mathrm{S}_{13}$.

values ranged from 361 to $497 \mathrm{~cm}^{2} \mathrm{Vs}^{-1}$ in this study. Bouyrie et al. [13] conducted a Korringa-Kohn-Rostoker calculation for $\mathrm{Cu}_{12} \mathrm{Sb}_{2} \mathrm{Te}_{2} \mathrm{~S}_{13}$, which yielded a band gap of $0.9 \mathrm{eV}$ lower than the $1.3 \mathrm{eV}$ of $\mathrm{Cu}_{12} \mathrm{Sb}_{4} \mathrm{~S}_{13}$. However, its electrical resistivity was higher than that of undoped $\mathrm{Cu}_{12} \mathrm{Sb}_{4} \mathrm{~S}_{13}$; therefore, they suggested that measurement of the Hall coefficient would be necessary to confirm this accurately. $\mathrm{Cu}_{12} \mathrm{Sb}_{4} \mathrm{~S}_{13}$ prepared using the same method as in our 


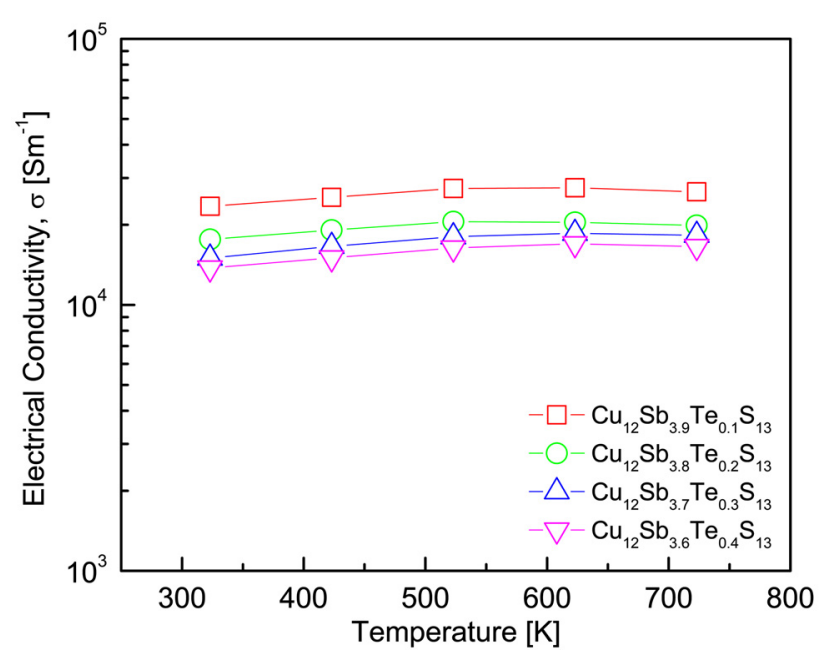

Fig. 4. Temperature dependence of the electrical conductivity for $\mathrm{Cu}_{12} \mathrm{Sb}_{4-\mathrm{y}} \mathrm{Te}_{\mathrm{y}} \mathrm{S}_{13}$.

previous study [15] exhibited a high carrier concentration of $3.12 \times 10^{20} \mathrm{~cm}^{-3}$ and low mobility of $4.35 \mathrm{~cm}^{2} \mathrm{~V}^{-1} \mathrm{~s}^{-1}$; however, in the present study, $\mathrm{Te}$ doping reduced the carrier concentration to $1.74 \times 10^{18} \mathrm{~cm}^{-3}$ and increased the mobility to $497 \mathrm{~cm}^{2} \mathrm{~V}^{-1} \mathrm{~s}^{-1}$. Measurement of the Hall coefficient of the tetrahedrite was problematic because of its very low value (almost zero) with large errors [16]. This made it difficult to analyze the experimental data on the charge transport properties of tetrahedrite.

Figure 4 shows the electrical conductivity of the $\mathrm{Cu}_{12} \mathrm{Sb}_{4-\mathrm{y}}$ $\mathrm{Te}_{\mathrm{y}} \mathrm{S}_{13}$. The electrical conductivity was relatively constant at temperatures from 323 to $723 \mathrm{~K}$, similar to nondegenerate semiconductor behavior. However, the conductivity decreased as the Te content increased (at a constant temperature), which was consistent with the change in carrier concentration according to the Te concentration (Figure 3). Bouyrie et al. [13] reported that the electrical resistivity of $\mathrm{Cu}_{12} \mathrm{Sb}_{4-\mathrm{y}} \mathrm{Te}_{\mathrm{y}} \mathrm{S}_{13}$ $(\mathrm{y}=0.5-2.0)$ decreased as the temperature increased, while it increased with Te content. Lu et al. [14] studied the electrical resistivity (conductivity) of $\mathrm{Cu}_{12} \mathrm{Sb}_{4-\mathrm{y}} \mathrm{Te}_{\mathrm{y}} \mathrm{S}_{13}(\mathrm{y}=0-1)$, which increased from $1.5 \times 10^{-5}$ to $3.7 \times 10^{-5} \Omega \mathrm{m}\left(6.7 \times 10^{4}\right.$ and 2.7 $\times 10^{4} \mathrm{Sm}^{-1}$, respectively) as the Te content increased at 723 $\mathrm{K}$. This is because Te doping at the $\mathrm{Sb}$ sites caused electrons to fill the valence band and reduced the number of available holes, that is, charge carriers. The electrical conductivity is affected by the carrier concentration (n) and mobility $(\mu)$, as shown by the following relation:

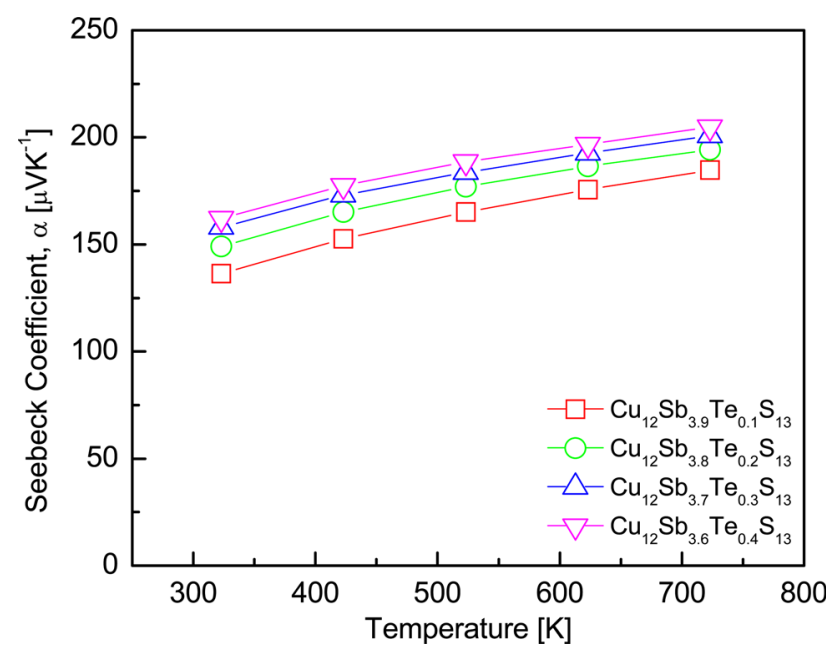

Fig. 5. Temperature dependence of the Seebeck coefficient for $\mathrm{Cu}_{12} \mathrm{Sb}_{4-\mathrm{y}} \mathrm{Te}_{\mathrm{y}} \mathrm{S}_{13}$.

$$
\sigma=\operatorname{en} \mu
$$

where e is the electron charge. In this study, the electrical conductivity decreased from $2.6 \times 10^{4} \mathrm{Sm}^{-1}$ for $\mathrm{Cu}_{12} \mathrm{Sb}_{3.9}$ $\mathrm{Te}_{0.1} \mathrm{~S}_{13}$ to $1.6 \times 10^{4} \mathrm{Sm}^{-1}$ for $\mathrm{Cu}_{12} \mathrm{Sb}_{3.6} \mathrm{Te}_{0.4} \mathrm{~S}_{13}$ at $723 \mathrm{~K}$, owing to the decreased carrier concentration caused by $\mathrm{Te}$ doping.

Figure 5 shows the Seebeck coefficients of the $\mathrm{Cu}_{12} \mathrm{Sb}_{4}$ ${ }_{y} \mathrm{Te}_{\mathrm{y}} \mathrm{S}_{13}$ compounds. All of the specimens exhibited positive values for the p-type semiconductor and agreed with the sign of the Hall coefficients. The Seebeck coefficient is expressed as:

$$
\alpha=\frac{8 \pi^{2} k_{B}^{2} m^{*} T}{3 e h^{2}}\left(\frac{\pi}{3 n}\right)^{2 / 3}
$$

where $\mathrm{k}_{\mathrm{B}}$ is the Boltzmann constant, $\mathrm{m}^{*}$ is the effective carrier mass, and $h$ is the Planck constant [17]. In general, the absolute value of Seebeck coefficient reaches a maximum at a certain temperature and then decreases with further increases in temperature because the carrier concentration increases rapidly owing to the intrinsic transition. The carrier concentration was decreased by Te doping; therefore, the intrinsic transition temperature should have been reduced. However, the intrinsic transition did not occur until $723 \mathrm{~K}$ in this study, possibly because of the low Te-doping levels. As a result, the intrinsic transition temperature of $\mathrm{Cu}_{12} \mathrm{Sb}_{4}$. ${ }_{\mathrm{y}} \mathrm{Te}_{\mathrm{y}} \mathrm{S}_{13}(\mathrm{y}=0.1-0.4)$ is expected to be $>723 \mathrm{~K}$. The Seebeck 


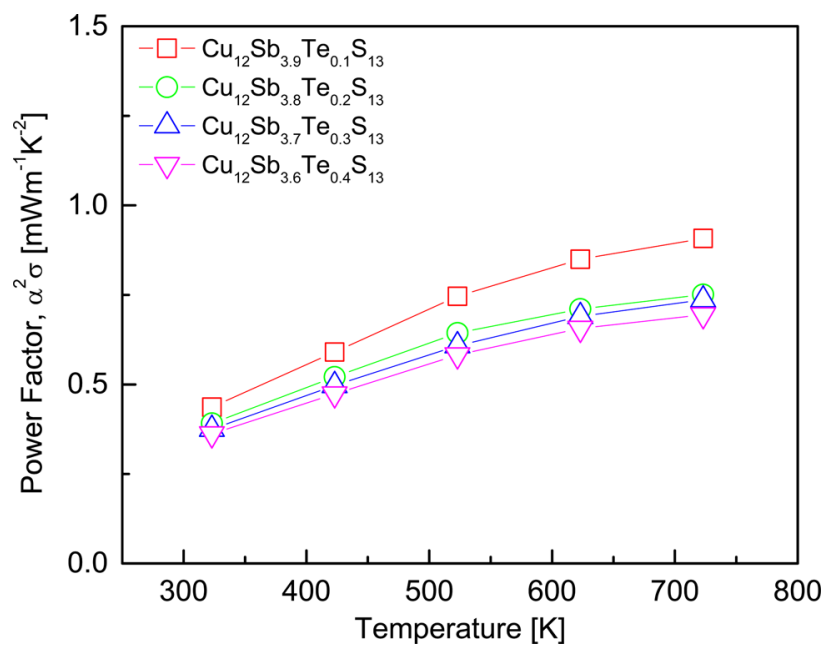

Fig. 6. Temperature dependence of the power factor for $\mathrm{Cu}_{12} \mathrm{Sb}_{4-y}$ $\mathrm{Te}_{\mathrm{y}} \mathrm{S}_{13}$.

coefficient increased as the Te concentration increased at a constant temperature, because it is inversely related to carrier concentration. Therefore, the Seebeck coefficient increased as the Te content increased (the carrier concentration decreased), and a maximum Seebeck coefficient of $204 \mu \mathrm{VK}^{-1}$ was obtained for $\mathrm{Cu}_{12} \mathrm{Sb}_{3.6} \mathrm{Te}_{0.4} \mathrm{~S}_{13}$ at $723 \mathrm{~K}$. This value was higher than the maximum Seebeck coefficient of $183 \mu \mathrm{VK}^{-1}$ at 723 $\mathrm{K}$ for the undoped $\mathrm{Cu}_{12} \mathrm{Sb}_{4} \mathrm{~S}_{13}$ reported in our previous study [15]. Bouyrie et al. [13] reported that the Seebeck coefficient of $\mathrm{Cu}_{12} \mathrm{Sb}_{4-\mathrm{y}} \mathrm{Te}_{\mathrm{y}} \mathrm{S}_{13}(\mathrm{y}=0.5-2.0)$ increased with increasing temperature and $\mathrm{Te}$ content. Lu et al. [14] achieved a Seebeck coefficient of $193 \mu \mathrm{VK}^{-1}$ at $723 \mathrm{~K}$ for $\mathrm{Cu}_{12} \mathrm{Sb}_{3} \mathrm{TeS}_{13}$, which was a $50 \%$ increase over that of undoped $\mathrm{Cu}_{12} \mathrm{Sb}_{4} \mathrm{~S}_{13}$.

Figure 6 presents the $\mathrm{PF}$ of $\mathrm{Cu}_{12} \mathrm{Sb}_{4-\mathrm{y}} \mathrm{Te}_{\mathrm{y}} \mathrm{S}_{13}$. As the temperature increased, the PF increased. PF has a trade-off relationship with the carrier concentration. In this study, the decrease in electrical conductivity had a greater effect than the increase in the Seebeck coefficient; thus, PF decreased as the Te content increased. The highest PF $\left(0.91 \mathrm{mWm}^{-1} \mathrm{~K}^{-2}\right)$ was achieved at $723 \mathrm{~K}$ for $\mathrm{Cu}_{12} \mathrm{Sb}_{3.9} \mathrm{Te}_{0.1} \mathrm{~S}_{13}$. However, this value was slightly lower than the value of $0.95 \mathrm{mWm}^{-1} \mathrm{~K}^{-2}$ at $723 \mathrm{~K}$ for the undoped $\mathrm{Cu}_{12} \mathrm{Sb}_{4} \mathrm{~S}_{13}$ in our previous study [15], due to the decrease in electrical conductivity from Te doping.

Figure 7 shows the thermal conductivity of the $\mathrm{Cu}_{12} \mathrm{Sb}_{4}$ ${ }_{y} \mathrm{Te}_{\mathrm{y}} \mathrm{S}_{13}$ compounds. The thermal conductivity exhibited values below $1.0 \mathrm{Wm}^{-1} \mathrm{~K}^{-1}$ at $323-723 \mathrm{~K}$ for all samples, as shown in Fig. 7(a). As the Te content increased, the value
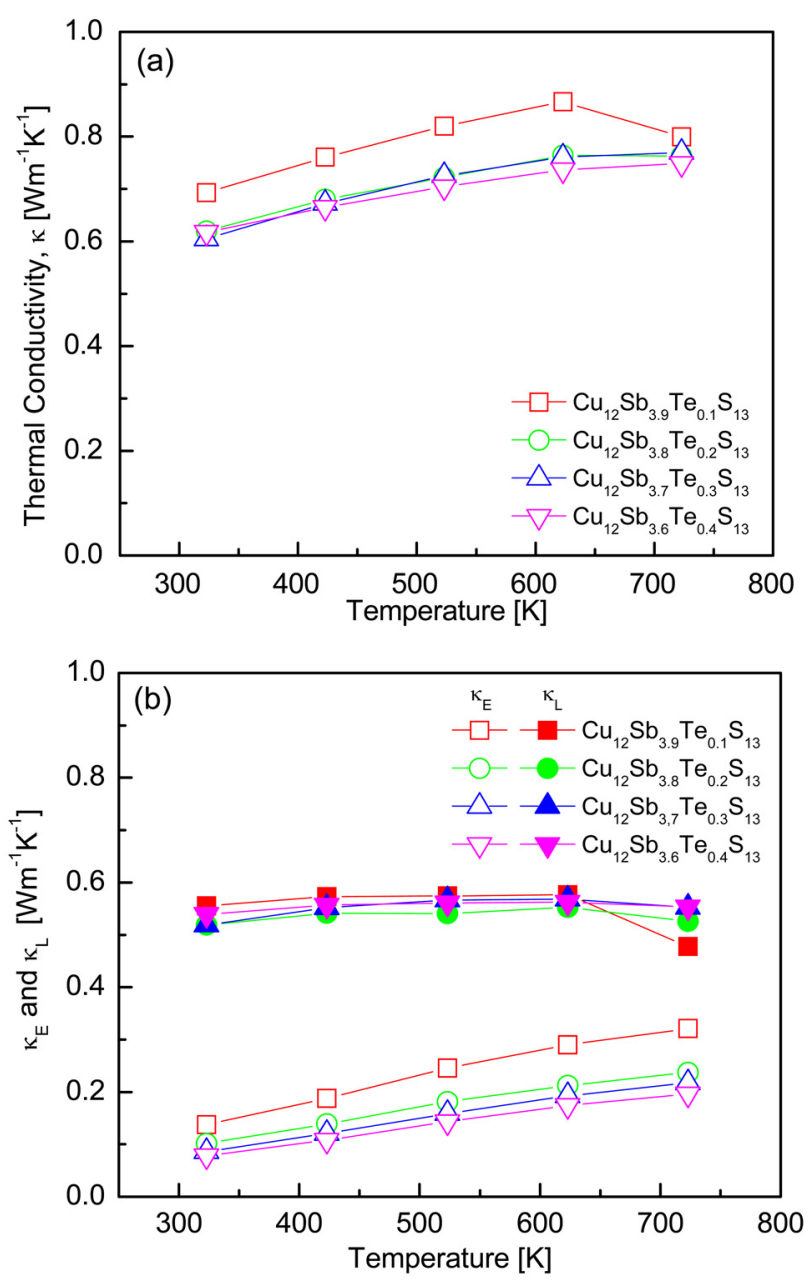

Fig. 7. Temperature dependence of the thermal conductivities for $\mathrm{Cu}_{12} \mathrm{Sb}_{4-\mathrm{y}} \mathrm{Te}_{\mathrm{y}} \mathrm{S}_{13}$ : (a) total thermal conductivity and (b) electronic and lattice thermal conductivities.

decreased from 0.69 to $0.61 \mathrm{Wm}^{-1} \mathrm{~K}^{-1}$ at $323 \mathrm{~K}$ and 0.80 to $0.75 \mathrm{Wm}^{-1} \mathrm{~K}^{-1}$ at $723 \mathrm{~K}$. The thermal conductivity of the undoped $\mathrm{Cu}_{12} \mathrm{Sb}_{4} \mathrm{~S}_{13}$ ranged from 0.72 to $0.77 \mathrm{Wm}^{-1} \mathrm{~K}^{-1}$ at 323-723 K [15], and the Te-doped specimens also maintained low thermal conductivity values in this study. Lu et al. [14] reported that as the Te content increased, the thermal conductivity of $\mathrm{Cu}_{12} \mathrm{Sb}_{4-\mathrm{y}} \mathrm{Te}_{\mathrm{y}} \mathrm{S}_{13}(\mathrm{y}=0-1)$ decreased; 0.64$0.77 \mathrm{Wm}^{-1} \mathrm{~K}^{-1}$ at $300-700 \mathrm{~K}$ for $\mathrm{Cu}_{12} \mathrm{Sb}_{3} \mathrm{TeS}_{13}$, which was approximately half that of undoped tetrahedrite. The thermal conductivity of a semiconductor is composed of two components: lattice thermal conductivity $\left(\kappa_{\mathrm{L}}\right.$ : phonon contribution) and electronic thermal conductivity $\left(\kappa_{\mathrm{E}}\right.$ : carrier contribution), and $\kappa_{\mathrm{E}}$ can be isolated by the WiedemannFranz law $\left(\kappa_{\mathrm{E}}=\mathrm{L} \sigma \mathrm{T}\right)$ [18]. The Lorenz number $(\mathrm{L})$ can be 
estimated from the relation [19]:

$$
\mathrm{L}=1.5+\exp (-|\alpha| / 116)
$$

and these values can be found in Table 1 . As the Te content increased, the Lorenz number decreased from $1.80 \times 10^{-8}$ to $1.74 \times 10^{-8} \mathrm{~V}^{2} \mathrm{~K}^{-2}$ at $323 \mathrm{~K}$ because of the increase in the Seebeck coefficient caused by the decreased carrier concentration.

Figure 7(b) presents the separated values of the lattice and electronic thermal conductivity. The electronic thermal conductivity increased with increasing temperature, ranging from 0.07 to $0.32 \mathrm{Wm}^{-1} \mathrm{~K}^{-1}$ at $323-723 \mathrm{~K}$. The electronic thermal conductivity decreased as the Te doping level increased because the carrier concentration decreased. At temperatures of 323-723 K, the lattice thermal conductivity was $<0.6 \mathrm{Wm}^{-1} \mathrm{~K}^{-1}$ regardless of the Te concentration. Bouyrie et al. [13] reported a similar lattice thermal conductivity $\left(<0.5 \mathrm{Wm}^{-1} \mathrm{~K}^{-1}\right)$ for $\mathrm{Cu}_{12} \mathrm{Sb}_{4-\mathrm{y}} \mathrm{Te}_{\mathrm{y}} \mathrm{S}_{13}(\mathrm{y}=0.5-$ 2.0), irrespective of $\mathrm{Te}$ content. Tetrahedrite has been reported to have inherently low thermal conductivity due to phonon scattering of the $\mathrm{Cu}$ atoms, bringing the lattice thermal conductivity closer to the theoretical minimum value [20].

Figure 8 shows the $\mathrm{ZT}$ for $\mathrm{Cu}_{12} \mathrm{Sb}_{4-\mathrm{y}} \mathrm{Te}_{\mathrm{y}} \mathrm{S}_{13}$. $\mathrm{ZT}$ increased with temperature because of the temperature dependence of $\mathrm{PF}$ and thermal conductivity. The highest value $(0.80)$ was obtained at $723 \mathrm{~K}$ for $\mathrm{Cu}_{12} \mathrm{Sb}_{3.9} \mathrm{Te}_{0.1} \mathrm{~S}_{13}$, which was higher

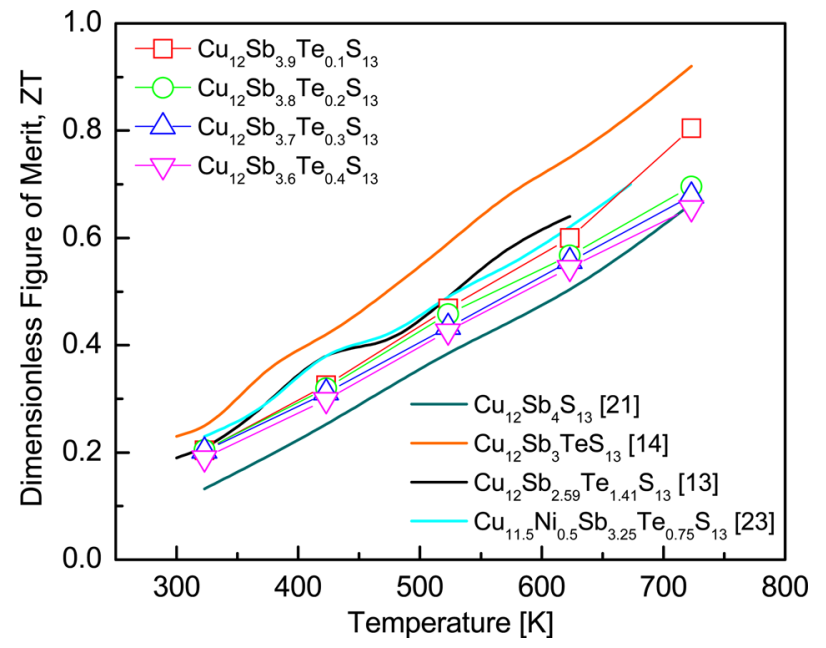

Fig. 8. Dimensionless figure of merit for $\mathrm{Cu}_{12} \mathrm{Sb}_{4-\mathrm{y}} \mathrm{Te}_{\mathrm{y}} \mathrm{S}_{13}$. than the ZT of 0.66 , at $723 \mathrm{~K}$ for undoped $\mathrm{Cu}_{12} \mathrm{Sb}_{4} \mathrm{~S}_{13}$ prepared under the same conditions by Pi et al. [21]. Barbier et al. [22] achieved a ZT of 0.60 , at $723 \mathrm{~K}$ for $\mathrm{Cu}_{12} \mathrm{Sb}_{4} \mathrm{~S}_{13}$ produced by EM and SPS. Therefore, Te doping is considered to be effective at enhancing the thermoelectric performance of tetrahedrite. Bouyrie et al. [13,23] reported ZT values of 0.65 and 0.70 , at $623 \mathrm{~K}$ for $\mathrm{Cu}_{12} \mathrm{Sb}_{2.59} \mathrm{Te}_{1.41} \mathrm{~S}_{13}$ and $\mathrm{Cu}_{11.5} \mathrm{Ni}_{0.5} \mathrm{Sb}_{3.25} \mathrm{Te}_{0.75} \mathrm{~S}_{13}$ synthesized by EM and SPS, respectively. Lu et al. [14] reported a ZT value of 0.92 at 723 $\mathrm{K}$ for $\mathrm{Cu}_{12} \mathrm{Sb}_{3} \mathrm{TeS}_{13}$ synthesized by EM and HP. As a result, in this study, Te-doped tetrahedrites with high thermoelectric performance could be synthesized by MA and HP without post-annealing as a solid-state method.

\section{CONCLUSIONS}

$\mathrm{Cu}_{12} \mathrm{Sb}_{4-\mathrm{y}} \mathrm{Te}_{\mathrm{y}} \mathrm{S}_{13}(\mathrm{y}=0.1-0.4)$ tetrahedrites doped with $\mathrm{Te}$ at the $\mathrm{Sb}$ sites were successfully synthesized without secondary phases using a MA-HP process. The HP produced densely sintered bodies with a relative density $>99.7 \%$. As the Te content increased, the lattice constant increased from 1.0334 to $1.0346 \mathrm{~nm}$, confirming the successful substitution of Te at the $\mathrm{Sb}$ sites. Additionally, as Te content increased, the electrical conductivity decreased, while the Seebeck coefficient increased due to reduced carrier concentration. $\mathrm{Cu}_{12} \mathrm{Sb}_{3.9} \mathrm{Te}_{0.1} \mathrm{~S}_{13}$ exhibited the highest $\mathrm{PF}$ of $0.91 \mathrm{mWm}^{-1} \mathrm{~K}^{-2}$ at $723 \mathrm{~K}$ because the decrease in electrical conductivity dominated the increase in Seebeck coefficient by $\mathrm{Te}$ doping. Further, as the $\mathrm{Te}$ content increased, the contribution of the decrease in electronic thermal conductivity was greater than that of the decrease in lattice thermal conductivity; thus, the total thermal conductivity decreased. As a result, the highest ZT (0.80) was obtained at $723 \mathrm{~K}$ for $\mathrm{Cu}_{12} \mathrm{Sb}_{3.9} \mathrm{Te}_{0.1} \mathrm{~S}_{13}$, which had high PF and low thermal conductivity.

\section{Acknowledgment}

This study was supported by the Basic Science Research Capacity Enhancement Project (National Research Facilities and Equipment Center) through the Korea Basic Science Institute funded by the Ministry of Education (Grant No. 2019R1A6C1010047). 


\section{REFERENCES}

1. G. J. Snyder and E. S. Toberer, Nat. Mater. 7, 105 (2008).

2. X. Lu and D. T. Morelli, Phys. Chem. Chem. Phys. 15, 5762 (2013).

3. A. Pfitzner, M. Evain, and V. Petricek, Acta Crystallogr. 53, 337 (1997).

4. Y. Bouyrie, C. Candolfi, S. Pailhès, M. M. Koza, B. Malaman, A. Dauscher, J. Tobola, O. Boisron, L. Saviot, and B. Lenoir, Phys. Chem. Chem. Phys. 17, 19751 (2015).

5. W. Lai, Y. Wang, D. T. Morelli, and X. Lu, Adv. Funct. Mater. 25, 3648 (2015).

6. E. Lara-Curzio, A. F. May, O. Delaire, M. A. McGuire, X. Lu, C. Y. Liu, E. D. Case, and D. T. Morelli, J. Appl. Phys. 115, 193515 (2014).

7. R. Chetty, A. Bali, and R. C. Mallik, J. Mater. Chem. 3, 12364 (2015).

8. S. Tippireddy, R. Chetty, M. H. Naik, M. Jain, K. Chattopadhyay, and R. C. Mallik, J. Phys. Chem. C. 122, 8743 (2018).

9. Y. Bouyrie, S. Sassi, C. Candolfi, J. B. Vaney, A. Dauscher, and B. Lenoir, Dalton Trans. 45, 7294 (2016).

10. X. Lu, D. T. Morelli, Yuxing. Wang, W. Lai, Yi. Xia, and V. Ozolins, Chem. Mater. 28, 1781 (2016).

11. D. S. P. Kumar, R. Chetty, O. E. Femi, K. Chattopadhyay, P. Malar, and R. C. Mallik, J. Electron. Mater. 46, 2616 (2017).

12. S. G. Kwak, J. H. Pi, G. E. Lee, and I. H. Kim, Korean J.
Met. Mater. 58, 272 (2020).

13. Y. Bouyrie, C. Candolfi, V. Ohorodniichuk, B. Malaman, A. Dauscher, J. Tobola, and B. Lenoir, J. Mater. Chem. C 3, 10476 (2015).

14. X. Lu and D. T. Morelli, J. Electron. Mater. 43, 1983 (2014).

15. S. Y. Kim, S. G. Kwak, J. H. Pi, G. E. Lee, and I. H. Kim, J. Electron. Mater. 48, 1857 (2019).

16. S. Tippireddy, R. Chetty, M. H. Nailk, M. Jain, K. Chattopadhyay, and R. C. Mallik, J. Phys. Chem. C 122, 8735 (2018).

17. Y. C. Lan, A. J. Minnich, G. Chen, and Z. F. Ren, $A d v$. Funct. Mater. 20, 357 (2010).

18. X. Yan, B. Poudel, Y. Ma, W. Liu, G. Joshi, H. Wang, Y. Lan, D. Wang, G. Chen, and Z. Ren, Nano Lett. 10, 3373 (2010).

19. H. Cailat, A. Borshchevsky, and J. P. Fleurial, J. Appl. Phys. 80, 4442 (1996).

20. R. Chetty, P. Kumar, G. Rogl, P. Rogl, E. Bauer, H. Michor, S. Suwas, S. Pucjegger, G. Giester, and R. C. Mallik, Phys. Chem. Chem. Phys. 17, 1716 (2015).

21. J. H. Pi, G. E. Lee, and I. H. Kim, J. Electron. Mater. 49 , 2710 (2020).

22. T. Barbier, P. Lemoine, S. Gascoin, O. I. Lebedev, A. Kaltzoglou, P. Vaqueiro, A. V. Powell, R. I. Smith, and E. Guilmeau, J. Alloys Compd. 634, 253 (2015).

23. Y. Bouyrie, C. Candolfi, J. B. Vaney, A. Dauscher, and B. Lennoir, J. Electron. Mater. 45. 1601 (2016). 